\title{
Effects of mycorrhiza on growth and essential oil production in selected aromatic plants
}

\author{
Waed Tarraf, Claudia Ruta, Francesca De Cillis, Anna Tagarelli, Luigi Tedone, \\ Giuseppe De Mastro \\ Department of Agricultural and Environmental Science, University Aldo Moro of Bari, Italy
}

\begin{abstract}
Arbuscular mycorrhizal (AM) symbiosis is widely investigated in aromatic herbs. Several studies have shown different effects on secondary metabolites, biomass production, as well as oil quantitative and qualitative aspects. The seeking to increase the yield of plants and their oils is an interesting topic in the world of medicinal and aromatic plant production. In tune with that, this study evaluated the effectiveness of two mycorrhiza fungi, Funneliformis mosseae (syn. Glomus mosseae) and Septoglomus viscosum (syn. Glomus viscosum), on three species from Lamiaceae family: Salvia officinalis L., Origanum vulgare L., and Thymus vulgaris L. besides untreated control. It was found that the effect of symbiosis on growth was more favourable with $S$. viscosum than other AM fungus. The $S$. viscosum inoculation raised the yield of essential oil in oregano. Analysis of gas chromatography/mass spectrometry showed that manool obtained the highest abundance in leaf essential oil of inoculated sage; thymol was the major component whatever the treatment in thyme and lower relative content of carvacrol was reported with arbuscular mycorrhizal fungi inoculation in oregano. The results suggest the mycorrhizal inoculation as a promising technology in sustainable agricultural system to improve the plant productivity performance. Specific inocula are strategic to enhance the chemical profile of essential oils.
\end{abstract}

Correspondence: Claudia Ruta, Department of Agricultural and Environmental Science (DiSAAT), University Aldo Moro of Bari, via Amendola 165/A, 70125, Bari, Italy.

Tel.: +39.080.5442975.

E-mail: claudia.ruta@uniba.it

Key words: Mycorrhiza; phosphorus; medicinal and aromatic plants.

Conference presentation: SIA XLIII Congress, Pisa, 2014.

Received for publication: 28 November 2014.

Revision received: 15 June 2015.

Accepted for publication: 20 June 2015.

(C) Copyright W. Tarraf et al., 2015

Licensee PAGEPress, Italy

Italian Journal of Agronomy 2015; 10:633

doi:10.4081/ija.2015.633

This article is distributed under the terms of the Creative Commons Attribution Noncommercial License (by-nc 3.0) which permits any noncommercial use, distribution, and reproduction in any medium, provided the original author(s) and source are credited.

\section{Introduction}

Most of medicinal and aromatic plants (MAP) are used around the world for different purposes. In general, products derived from secondary metabolism are responsible for the efficacy of medicinal plants, for food and pharmaceutical industries (Cabello et al., 2005), for their antimicrobial potential (Bagamboula et al., 2004), and for their natural properties as sources of phytochemicals and active compounds (Toussaint 2007; Toussaint et al., 2007).

Since the low productivity and poor quality of MAP production, are results of different factors like climatic conditions, seasonal variations, geographic sites, harvest periods and agronomic management of the crop, building up a strategy for a large scale production of MAP with constant composition combined with high amounts of the active compounds is a basic goal for global market. Thus, it is of interest to define cropping systems to improve essential oils yield by an adequate use of irrigation (Moro et al., 2011), chemical fertilisers and plant growth regulators (Prins et al., 2010).

Although chemical fertilisers greatly lead to improve the yield and quality of aromatic plants production, their application has to be balanced ensuring the safety of the products obtained as well as the environment (Watson et al., 2002). In order to reduce the agrochemical input, effective soil management along with exploitation of mycorrhiza fungi to increase the uptake of plant nutrients can be planned (Kapoor et al., 2004). The fungal symbionts have acquired a great reputation in the biofertilisation and crop production since the close contact between plant roots and fungus hyphae creates bidirectional nutrient transfer between plant-fungus (Smith et al., 2004). The fungi increase the uptake of relatively immobile phosphate ions, while the host plant supplies the fungus with carbohydrates (Smith and Read, 1997). Since the symbiotic associations by arbuscular mycorrhiza (AM) fungi could induce plant to absorb more easily phosphorus (Smith and Read, 2008) that affects mainly the biosynthesis of essential oil (Loomis and Corteau, 1972), the aim of present study was to evaluate the effects of different inoculants of AM fungi on the growth, essential oil content and composition of Salvia officinalis L., Origanum vulgare L., and Thymus vulgaris $\mathrm{L}$.

\section{Materials and methods}

\section{Plant material}

Seeds of $S$. officinalis L. cv Regula (sage), O. vulgare L. spp. viridulum (Martrin-Donos) Nyman $\times 0$. vulgare L. spp. hirtum (Link) Iestwaart, cv Carva (oregano) and T. vulgaris L. cv Varico 3 (thyme) were provided by mediSeeds Sàrl (Conthey, Switzerland). 


\section{Experimental design}

The experimental trial was conducted at a glasshouse located at the Department of Agriculture and Environmental Science (DiSAAT), University Aldo Moro of Bari, Italy. Seeds of the three species were sown in 3 -L pots, contained an autoclaved substrate $\left(20 \mathrm{~min}\right.$ at $\left.120^{\circ} \mathrm{C}\right)$, consisting of soil, sand and perlite $(1: 1: 1 \mathrm{v} / \mathrm{v} / \mathrm{v})$, under controlled conditions with temperature range $\left(23-25^{\circ} \mathrm{C}\right)$ and a relative humidity $(\mathrm{RH}=50 \%)$ in a complete randomised design, including two mycorrhizal inoculants Funneliformis mosseae H.T. Nicolson (G.M) and Septoglomus viscosum Nicol. \& Gerd (G.V), besides one unfertilised and non-AM fungus control. The fungi were initially provided by the Department of Crop Plant Biology (University of Pisa, Italy) and then were multiplied on strawberry (Fragaria $\times$ Ananassa L) plants chosen for their high mycotrophy according to Dalpé and Monreal's method (2004). Each inoculum consisted of sand soil containing spores, external mycelium, and infected root fragments.

The mycorrhizal infection was done by adding $30 \mathrm{~g}$ (about 300 spores) to each pot of $F$. mosseae or $S$. viscosum inoculum before sowing. Seven replications were used for each treatment where one replicate represented by a single pot with three plants.

\section{Biometric parameters and arbuscular mycorrhiza colonisation}

After 4 months of growth, the plants were harvested. The shoot dry weight was evaluated and the density of glandular trichomes was determined by counting the peltate hairs using stereomicroscopy (Leica DMLB100; Leica Microsystems GmbH, Wetzlar, Germany), in the central portion of an abaxial surface on representative leaves, having the same age and position. The roots were cleared and stained according to Phillips and Hayman (1970). The assessment of mycorrhizal colonization was done following slide method (Giovannetti and Mosse, 1980). The aforementioned parameters were performed starting from plants selected randomly from each treatment.

\section{Extraction of the essential oil}

Air-dried leaves of plants were submitted to water distillation in a Clevenger type-apparatus with a flask of $500 \mathrm{~mL}$ and $250 \mathrm{~mL}$ water for $4 \mathrm{~h}$, as per the European Pharmacopeia standards (Council of Europe, 2007).

\section{Gas chromatography/mass spectrometry analysis}

The essential oil was analysed using gas chromatograph Agilent $6890 \mathrm{~N}$ coupled to an Agilent mass spectrometer 5973N (Agilent Technologies, Cernusco sul Naviglio, MI, Italy). Volatile components were separated on a capillary column HP-5MS (5\%- phenylmethypolysiloxane, $0.25 \mathrm{~mm} \times 30 \mathrm{~m} \times 0.25 \mu \mathrm{m}$ film thicknesses). The temperature of injector and transfer line were set to 250 and 300 respectively. The oven was heated to $60^{\circ} \mathrm{C}$, subsequently $3.0^{\circ} \mathrm{C} / \mathrm{min}$ up to $240^{\circ} \mathrm{C}$, then up to 280 to be hold for $5 \mathrm{~min}$. The following conditions were adopted: split ratio 1:25, at flow $1.1 \mathrm{~mL} \mathrm{~min}^{-1}$, with helium as carrier gas, and injection volume of $1 \mu \mathrm{L}$ of essential oil diluted in dichloromethane (1:300 v/v). The acquisition data and instrument control were carried out using ChemStation software (G1701DA, version D.03.00.611). The components of the essential oils were identified by comparison of their retention indices relative to (C8-C30) $n$-alkanes (Sigma, Milan, Italy), either with those from the literature or Wiley 7 n.L mass spectral library.

\section{Statistical analysis}

The collected data were subjected to analysis of variance according to a completely randomised design using the Statistical Analysis System Version 9 (SAS V9; SAS Institute, Inc., Cary, NC, USA); the sig- nificance of differences between treatments was determined by Duncan's multiple range test.

\section{Results and discussion}

The AM fungal species colonised the host plants successfully with high percentage (data not shown). Results of shoot biomass reported different mycorrhizal effects depending on the species of plant and fungus, as shown in Figure 1. The positive response of inoculated shoots was translated into an increasing of dry weight whatever the inoculants, both in oregano and sage. The best inoculation efficiency was shown by oregano mycorrhized by $S$. viscosum, with an increase of 3 fold biomass compared to the control. According to previous studies of Klironomos (2003), Munkvold et al. (2004) and Smith et al. (2004) the application of different AM inoculants leaded to different responds in the plants. Generally, mycorrhizal plants increased the shoot dry weight in accordance with finding on $O$. vulgare plants inoculated with Glomus mosseae (Khaosaad et al., 2006) or Glomus etunicatum (Karagiannidis et al., 2012).

Higher density of glandular trichomes was observed in leaves collected from mycorrhizal plants (Figure 2). Data showed that the best

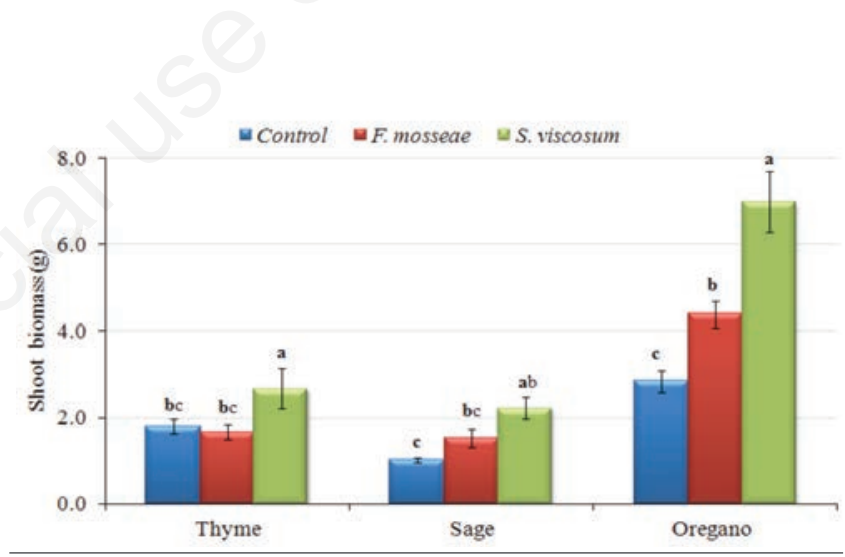

Figure 1. Shoot biomass in three species of Lamiaceae family inoculated with Funneliformis mosseae or Septoglomus viscosum compared to uninoculated plants (control). Values with different letters are statistically significant at 0.05 (Duncan's test).

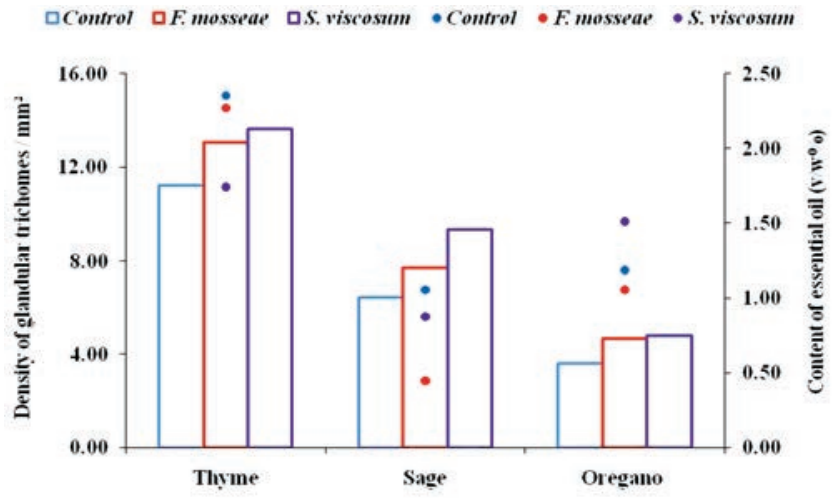

Figure 2. Density of glandular trichomes $/ \mathrm{mm}^{2}$ and the content of essential oil $(\mathrm{v} / \mathrm{w} \%)$ in thyme, sage, and oregano inoculated with Funneliformis mosseae or Septoglomus viscosum, 120 days after mycorrhizal inoculation. 
inoculum was $S$. viscosum in term of essential oils yield obtained from oregano, whereas the colonisation in T. vulgaris $L$. and $S$. officinalis $L$. has no effect on oil accumulation once compared to the control (Figure 2). Several studies on many species of Lamiaceae family, such as Mentha arvensis (Freitas et al., 2004), Ocimum basilicum (Copetta et al., 2006) and Origanum sp. (Khaosaad et al., 2006) described consistent findings about increasing the oil quantity in favour of inoculation by AM fungi. The major role of AM to improve the quantitative and qualitative yield of essential oils has been proved (Kapoor et al., 2002, 2004). In our study not only the quantitative aspect affected by AM species but also the chemical profile of oil was changed. Thymol was the major component (Lee et al., 2005) among all the identified compounds regardless of the three thyme treatments. $F$. mosseae leaded to high content of thymol $(66.66 \%)$, while its precursor $\rho$-cymene increased with $S$. viscosum (13.01\%). Whereas the treatments determined significant differences regarding the percentage of measured compounds and oil quality in S. officinalis, particularly mycorrhizal symbiosis produced an increase in the amount of manool with a decrease of cis-thujone. This chemical profile of the inoculated plants is usually found in some $S$. officinalis biotype from Cuba (Pino et al., 1997). In Origanum vulgare, carvacrol was the most abundant component $(69.40-77.73 \%)$, followed by thymol $(5.80-13.84 \%), \gamma$-terpinene (3.86-5.45\%), $\rho$-cymene (2.43-4.67\%) and trans-caryophyllene (3.02$3.40 \%)$. Even if the percentages of carvacrol and thymol were different depending on mycorrhizal treatments and in comparison to the control, the total amount of phenolic monoterpenoids and their precursors $(\gamma$ terpinene and $\rho$-cymene) was quite similar.

\section{Conclusions}

This study confirmed the role of AM fungi in the productivity performance of aromatic plants; all the three species demonstrated an increase in biomass in symbiosis presence, as already reported by previous studies in the literature. The inoculation with AM fungi can reflect a friendly strategy to enhance the sustainability of the agricultural practices and the production of bioactive molecules in the Lamiaceae species studied. Even if the positive effect of AM fungi on biomass production or the content of bioactive compounds in aromatic plants is not general, but it depends on the specific plant-AM fungus interaction and the bioactive compound.

\section{References}

Bagamboula CF, Uyttendaele M, Debevere J, 2004. Inhibitory effect of thyme and basil essential oils, carvacrol, thymol, estragol, linalool and p-cymene towards Shigella sonnei and S. flexneri. Food Microbiol. 21:33-42.

Cabello M, Irrazabal G, Bucsinszky AM, Saparrat M, Schalamuk S, 2005. Effect of an arbuscular mycorrhizal fungus, Glomus mosseae, and a rock-phosphate-solubilizing fungus, Penicillium thomii, on Mentha piperita growth in a soilless medium. J. Basic Microbiol. 45:182-9.

Copetta A, Lingua G, Berta G, 2006. Effects of three AM fungi on growth, distribution of glandular hairs, and essential oil production in Ocimum basilicum L. var. Genovese. Mycorrhiza 16:485-94.

Council of Europe, 2007. European Pharmacopoeia, Ph. Eur. 6.0. $6^{\text {th }}$ ed. Council of Europe, Strasbourg, France.
Dalpé Y, Monreal M, 2004. Arbuscular mycorrhiza inoculum to support sustainable cropping systems. Crop Manage. Available from: http://www.plantmanagementnetwork.org/pub/cm /review/2004/ amfungi/

Freitas MSM, Martins MA, Curcino Vieira I J, 2004. Yield and quality of essential oils of Mentha arvensis in response to inoculation with arbuscular mycorrhizal fungi. Pesquisa Agropec. Brasil. 39:887-94.

Giovannetti M, Mosse B, 1980. An evaluation of techniques for measuring infection vesicular-arbuscular mycorrhizal in roots. New Phytol. 84:489-500.

Kapoor R, Giri B, Mukerji AG, 2002. Mycorrhization of coriander (Coriandrum sativum L.) to enhance the concentration and quality of essential oil. J. Sci. Food Agric. 82:339-42.

Kapoor R, Giri B, Mukerji KG, 2004. Improved growth and essential oil yield and quality in Foeniculum vulgare mill on mycorrhizal inoculation supplemented with P-fertiliser. Bioresour. Techn. 93:307-11.

Karagiannidis N, Thomidis T, Panou-Filotheou E, Karagiannidou C, 2012. Response of three mint and two oregano species to Glomus etunicatum inoculation. Austr. J. Crop Sci. 6:164-9.

Khaosaad T, Vierheilig H, Nell M, Zitterl-Eglseer K, Novak J, 2006. Arbuscular mycorrhiza alter the concentration of essential oils in oregano (Origanum sp., Lamiaceae). Mycorrhiza 16:443-6.

Klironomos JN, 2003. Variation in plant response to native and exotic arbuscular mycorrhizal fungi. Ecology 84:2292-301.

Lee SJ, Umano K, Shibamoto T, Lee KG, 2005. Identification of volatile components in basil (Ocimum basilicum L.) and thyme leaves (Thymus vulgaris L.) and their antioxidant properties. Food Chem. 91:131-7.

Loomis WD, Corteau R, 1972. Essential oil biosynthesis. Rec. Adv. Phytochem. 6:147-85.

Moro A, Zalacain A, Hurtado de Mendoza J, Carmona M, 2011. Effects of agronomic practices on volatile composition of Hyssopus officinalis L. essential oils. Molecules 16:4131-9.

Munkvold L, Kjøller R, Vestberg M, Rosendahl S, Jakobsen I, 2004. High functional diversity within species of arbuscular mycorrhizal fungi. New Phytol. 164:357-64.

Phillips JM, Hayman DS, 1970. Improved procedures for clearing roots and staining parasitic and vesicular-arbuscular mycorrhizal fungi for rapid assessment of infection. Trans. Br. Mycol. Soc. 55:158-61.

Pino JA, Estarrón M, Fuentes V, 1997. Essential oil of sage (Salvia officinalis L.) grown in Cuba. J. Essent. Oil Res. 9:221-22.

Prins CL, Vieira IJC, Freitas SP, 2010. Growth regulators and essential oil production. Braz. Soc. Plant Physiol. 22:91-102.

Smith SE, Smith FA, Jakobsen I, 2004. Functional diversity in arbuscular mycorrhizal (AM) symbioses: the contribution of the mycorrhizal $P$ uptake pathway is not correlated with mycorrhizal responses in growth or total P uptake. New Phytol. 162:51124.

Smith SE, Read DJ, 1997. Mycorrhizal symbiosis. Academic Press Ltd., London, UK.

Smith SE, Read DJ, 2008. Mycorrhizal symbiosis, 3rd ed. Academic Press, London, UK.

Toussaint JP, 2007. Investigating physiological changes in the aerial parts of AM plants: what do we know and where should we be heading?. Mycorrhiza 17:349-53.

Toussaint JP, Smith FA, Smith SE, 2007. Arbuscular mycorrhizal fungi can induce the production of phytochemicals in sweet basil irrespective of phosphorus nutrition. Mycorrhiza 17:291-7.

Watson CA, Atkinson D, Gosling P, Jackson LR, Rayns FW, 2002. Managing soil fertility in organic farming systems. Soil Use Manage. 18:239-47. 